\title{
Multi-Energy Synergistic Optimization of Regional Energy Internet Considering Demand Side Responses
}

\author{
Ran Li ${ }^{1, a}$, Yiqun Liu ${ }^{1, b, *}$, Ming Zeng ${ }^{1, c}$, Songsong Chen ${ }^{2, d}$, Mingzhu Li ${ }^{1, e}$, \\ Wenjun Ruan ${ }^{3, f}$
}

${ }^{1}$ North China Electric Power University, Beijing 102206, China

${ }^{2}$ China Electric Power Research Institute, Beijing 100192, China

${ }^{3}$ State Grid Jiangsu Electric Power Company, Nanjing 210029, China

a343823152@qq.com, b280255647@qq.com, 'zengmingbj@vip.sina.com, d18612499423@163.com, e657234170@qq.com, 'whlyq53327@sina.com

Keywords: regional energy internet, demand side responses, multi-energy synergistic, PSO-EO algorithm.

\begin{abstract}
Regional energy internet is the key to achieving multi-energy synergistic optimization and efficient use of energy at the regional level. This paper focuses on the multi-energy synergistic optimization of regional energy internet and constructs a model based on demand side responses, considering total system operating costs, energy saving rate and emission reduction rate. A PSO-EO algorithm is proposed to solve the multi-objective and nonlinear optimization model [1-2]. The proposed model and algorithm are applied to an actual regional energy internet in China. Result shows that the proposed model and algorithm can optimize the operation of the system (with a reduction in the total system cost of $21.9 \%$, the energy saving rate of $15.4 \%$ and the emission reduction rate of $19.1 \%$ ) and have remarkable social and economic benefits.
\end{abstract}

\section{Introduction}

At present, as China is facing changes in energy supply and demand pattern, environmental climate crisis and energy security crisis and other challenges, the energy revolution needs to be further deepened and implemented. As the strategic support and boost power of the energy revolution, energy internet which can comprehensively utilize multi-energy to achieve horizontal multi-energy synergistic optimization and vertical 'generation-grid-load-storage' coordination is accelerating the pace of construction and development [3-5]. Regional energy internet is a concrete manifestation of energy internet in terms of geographical division and functional realization. It contains electricity, gas, heat and other energy coupling and integration mechanism and can promote efficient, synergistic, complementary energy utilization and the local consumption of distributed renewable energy with good economic and social benefits [6]. We can control the resources to further promote the flexibility of load supply and promote the construction of the new, interactive and coordinate power supply and utilization system compatible with demand-side resources.

The current research on regional energy internet is still in its infancy. In [7-8], the underlying technology of developing regional energy internet is presented from the conceptual architecture level. It enriches the connotation of regional energy internet from the concept, providing development advice for regional energy consumption, energy use, energy distribution and future energy network construction. In [9-10], technology, related infrastructure construction, cooperation mechanisms and related policies of regional energy internet are introduced from the planning and development level.

In summary, the existing papers rarely proposed optimization analysis model for the dispatch management of regional energy internet. There were even fewer researches about regional energy internet optimization analysis compatible with demand-side resources. On this basis, this paper constructs a multi-objective optimization model of regional energy internet based on demand side responses. The PSO-EO algorithm is proposed to solve the above model. Finally, the proposed model 
is applied to an actual regional energy internet in China, using Matlab to realize the optimization of system operation strategy.

\section{Regional energy internet system}

Regional energy internet can achieve a tight coupling of electricity, natural gas, heat and other energy in a certain area. Its system application architecture is shown in Fig. 1. As an important adjustable load and key equipment in the regional energy internet system, energy storage equipment can participate in system energy optimization management. Taking the diversity of distributed generation and the characteristics of load output into account, on the one hand, it can improve the user experience and ensure the economic efficient operation of the system; on the other hand, it can effectively promote wind energy, photovoltaic and other new energy consumption needs. There are a wide range of energy sources in the energy side of regional energy internet, including a variety of distributed renewable energy such as wind energy, light energy, biomass energy, and traditional fossil fuels, etc. The large-scale consumption of distributed renewable energy can help promote regional energy consumption structure under the trend of low-carbon and promote energy conservation and emission reduction. Electric energy and thermal energy generated by energy side are linked by combined heat and power system, which can coordinate the electric and heat allocation of regional energy internet and meet the energy needs of multiple loads within the system. Electric energy and thermal energy generated by energy side reach load side through the energy conversion equipment, including the normal load and the adjustable load. In the load side, the adjustable load is represented by the energy storage equipment. Regional energy internet transports and transmits information with energy management system, distribution network, heating network, energy side and energy conversion side to achieve the coordination and scheduling of multiple energy sources.

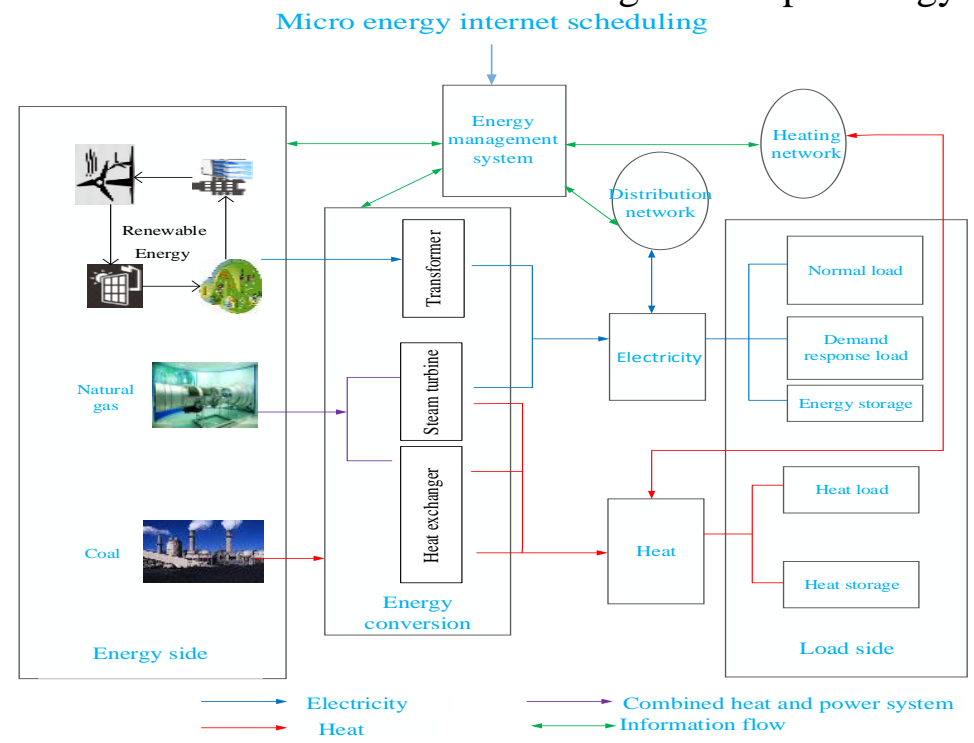

Fig. 1. Regional energy internet application architecture

\section{System modeling}

\subsection{Hypothesis}

(1) The power supplied by the public grid is supplied entirely by the coal and electricity units.

(2) Users' demand for cold using is achieved by absorption refrigerator and electric refrigerator, and the demand for heat using includes heating and hot water.

(3) Only the steady-state model of the system is studied, and the transient model of the system is not considered.

(4) The power generated by generating units take "grid-connected and feed-in" as its operation strategy, purchase electricity to the power grid when the power is insufficient, selling electricity to the grid when the power is surplus. 
(5) In this paper, in order to simplify the calculation the power suppliers of the regional energy Internet system is only composed of distributed PV, distributed wind power, distributed triple supply, energy storage equipment, etc.

\subsection{Objective function}

(1)System cost

The total cost of regional energy internet includes running cost and net purchase cost to power grid, the formula is as follows.

$$
C=C_{P V}+C_{\text {gas }}+C_{\text {wind }}+C_{\text {cold }}+C_{b a}+C_{\text {pipe }}-\left(C_{\text {purc }}-D_{\text {sale }}\right)
$$

In this formula, $C$ indicates total system cost, $C_{P V}, C_{\text {gas }}, C_{\text {wind }}, C_{\text {cold }}, C_{b a}$ and $C_{\text {pipe }}$ represent the operation cost of photovoltaic units, natural gas internal combustion engines, wind turbines, refrigerators, batteries, pipelines respectively. And $D_{\text {sale }}$ means electricity sales income.

(2) System energy conservation efficiency

This index mainly means the benefits of energy storage and demand response to system renewable energy, under the highly information-based scheduling.

$$
\begin{gathered}
\partial=\frac{1 / \eta_{C C H P}-1 / \eta_{M E I}}{1 / \eta_{C C H P}}=1-\frac{\eta_{C C H P}}{\eta_{M E I}} \\
\eta_{M E I}=\frac{G_{\text {total }}-\left(G_{c w}+G_{c p}\right)}{\frac{G_{\text {total }}}{\eta_{C C H P}}-G_{c w} \lambda_{c w}-G_{c p} \lambda_{c p}}
\end{gathered}
$$

In this formula, $\partial_{\text {cold }}$ means system energy conservation efficiency, $\eta_{\text {equl }}$ indicates equivalent power

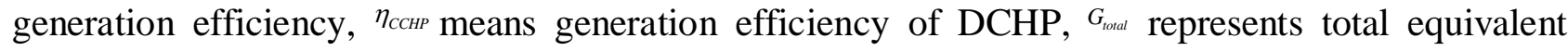
electricity, $G_{c w}$ means reduced abandoned wind power, $G_{c p}$ means reduced abandoned photovoltaic power, $\lambda_{c w}$ represents unit wind energy consumption coefficient and $\lambda_{c p}$ represents unit photoelectric energy consumption coefficient.

(3) System emission reduction efficiency

This index means the pollutant emission reduction rate that equals to reduced abandoned wind and photovoltaic power, and the improvement of power generation efficiency.

$$
\ell=\frac{2 \frac{\left(G_{c w}+G_{c p}\right)}{\eta_{C C H P}} E_{\text {gaco }}-\frac{\left(G_{c w}+G_{c p}\right)}{\eta_{M E I}} \cdot E_{\text {eaco }}}{\frac{G_{\text {total }}}{\eta_{C C H P}} \cdot E_{\text {gaco }}}
$$

In this formula, $\ell$ means system pollutant emission reduction rate, $E_{\text {gac }}$ means pollutant emission coefficient of natural gas CCHP system, and $E_{\text {eaco }}$ means system pollutant emission coefficient.

\subsection{Constraint condition}

1.Equipment operation constraint

(1) Generator operation constraint

1) Operation constrains of PV unit

$$
\begin{gathered}
P_{P V}(t)=\min \left\{P_{\text {capa }}, \theta(t) \cdot S_{P V} \cdot \eta_{P V}\right\} \\
P_{\min }^{P V} \leq P_{P V}(t) \leq P_{\max }^{P V}
\end{gathered}
$$

In this formula, $P_{P V}(t)$ means electric power of PV unit of time $\mathrm{t}, P_{\text {capa }}$ means rated installed capacity of PV unit, $\eta_{P V}$ means generation efficiency of PV unit, $\theta(k)$ means local solar radiation, $S_{P V}$ means area of solar panels, $P_{\min }^{P V}$ and $P_{\max }^{P V}$ indicate the minimum and maximum power generation respectively.

2) Operation constrains of natural gas internal-combustion engine unit

$$
\begin{gathered}
P_{\min }^{\text {gas }} \leq P_{\text {gas }}(t) \leq P_{\max }^{\text {gas }} \\
P_{\text {gas }}(t)-P_{\text {gas }}(t-1) \leq U P_{\text {gas }} \cdot \Delta t \\
P_{\text {gas }}(t)-P_{\text {gas }}(t-1) \geq-D N_{\text {gas }} \cdot \Delta t
\end{gathered}
$$

In this formula, $P_{\text {gas }}(t)$ represents the power generation of gas turbine of time $\mathrm{t}, P_{\min }^{\text {gas }}$ and $P_{\max }^{\text {gas }}$ represent the minimum and maximum power generation respectively, $U P_{g a s}$ and $D N_{g a s}$ represent the ramp up and ramp down rate of gas turbine. 
3) Operation constrains of wind turbine generators

$$
\begin{gathered}
P_{\min }^{\text {wind }} \leq P_{\text {wind }}(t) \leq P_{\max }^{\text {wind }} \\
0 \leq v(t) \leq v_{\text {in }} \text { 或 } v(t) \geq v_{\text {out }} \\
\left\{\begin{array}{c}
0 \\
P_{\text {wind }}(\mathrm{t})=\left(P_{\text {rate }}^{3} /\left(v_{\text {rate }}^{3}-v_{\text {in }}^{3}\right)\right)[v(t)]^{3}-\left(v_{\text {in }}^{3} /\left(v_{\text {rate }}^{3}-v_{\text {in }}^{3}\right)\right) P_{\text {rate }} \quad v_{\text {in }} \leq v(t) \leq v_{\text {rate }} \\
P_{\text {rate }} \\
v_{\text {rate }} \leq v(t) \leq v_{\text {out }}
\end{array}\right.
\end{gathered}
$$

In this formula, $P_{\text {vind }}(t)$ indicates the power generation of wind turbine generators of time $\mathrm{t}, P_{\min }^{\text {vima }}$ and $P_{\max }^{\text {vimd }}$ indicate the minimum and maximum power generation of wind turbine generators respectively,

$P_{\text {rate }}$ means rated output power of unit, $v_{\text {in }}$ and $v_{\text {out }}$ indicate cut-in wind speed and cut-out wind speed, $v_{\text {rate }}$ means rated wind speed.

(2) Refrigerator operation constraint

$$
\begin{aligned}
& 0 \leq P_{\text {cold }}^{\mathrm{i} n s o}(t) \leq P_{\text {cold }}^{\mathrm{i} n s o, \max }(t) \\
& 0 \leq P_{\text {cold }}^{\text {elec }}(t) \leq P_{\text {cold }}^{\text {elec, max }}(t)
\end{aligned}
$$

In this formula, $P_{\text {cold }}^{\mathrm{inso}}(t) 、 P_{\text {cold }}^{\mathrm{inss}, \max }(t)$ indicate the refrigerating power and the maximum power of absorption refrigerator respectively, $P_{\text {cold }}^{\text {elec }}(t) 、 P_{\text {cold }}^{\text {elec } \max (t)}$ indicate the refrigerating power and the maximum power of electric refrigerator respectively.

(3) Energy storage device operation constraint

In order to simplify the model, only the operation constraint of accumulator is considered in this paper.

$$
\begin{aligned}
0 & \leq P_{\text {bain }}(t) \leq P_{\max }^{\text {bain }}(t) \\
0 & \leq P_{\text {baout }}(t) \leq P_{\max }^{\text {baout }}(t) \\
P_{\max }^{\text {bain }}(t) & =\frac{G_{\max }^{\text {barate }}-(1-\sigma) G_{\text {barest }}(t-1)}{\eta_{\text {bain }} \cdot \Delta t} \\
P_{\max }^{\text {baout }}(t) & =\frac{(1-\sigma) G_{\text {barest }}(t-1)-G_{\min }^{\text {barate }}}{\Delta t \cdot \eta_{\text {boout }}}
\end{aligned}
$$

In this formula, $P_{\text {bain }}(t)$ and $P_{\text {baout }}(t)$ mean the charging and discharge power of accumulator of time $\mathrm{t}$ respectively, $P_{\max }^{\text {bain }}(t)$ and $P_{\max }^{\text {baut }}(t)$ indicate the maximum charging and discharge power of accumulator, $\sigma$ represents self-discharge rate of energy storage device, $\eta_{\text {bain }}$ and $\eta_{\text {baout }}$ indicate the charging and discharge power of energy storage device respectively, $G_{\max }^{\text {barate }}$ and $G_{\min }^{\text {bara }}$ indicate the maximum and minimum energy storage capacity respectively.

(4) Pipeline operation constraint

$$
\begin{gathered}
T_{\text {envir }}\left\{\begin{array}{c}
T_{\text {pipe }}^{\text {out }}=\left(T_{\text {pipe }}^{\text {in }}-T_{\text {envir }}\right)(1-\varepsilon)+T_{\text {envir }} \varepsilon \leq 1 \\
\varepsilon>1
\end{array}\right. \\
\varepsilon=\frac{\psi L}{c_{0} R_{\text {pipe }}}
\end{gathered}
$$

In this formula, $T_{\text {pipe }}^{\text {in }}$ and $T_{\text {pipe }}^{\text {out }}$ represent the temperature of inlet and outlet of pipeline, $T_{\text {envir }}$ means environment temperature, $\psi$ means heat transfer coefficient per unit length of pipeline, and $R_{\text {pipe }}$ pipeline water flow.

(5) Demand response constraint

Peak valley TOU price is an effective demand response mode, microgrid revenue and power system reliability can be improved by peak shaving and valley filling. In addition, because of the relatively low real-time requirement of energy storage optimization configuration, the paper constructs demand response constraints based on peak valley TOU price.

Electricity is a special commodity, the purchase behavior of electricity users is affected by the price of electricity. Near the equilibrium point in the electricity market, the price o is linear with electricity Q.

$$
Q=-a \cdot o+b
$$


In this formula, a, b is the relevant parameters.

Under the peak-valley price, users will adjust the power structure, the price level will not only affect the load at this time, but also other time. Self-elasticity coefficient and cross elasticity coefficient at peak period is as follows.

$$
\begin{aligned}
& n_{p}=\frac{-a_{p} o_{p}}{-a_{p} o_{p}+b_{p}} \\
& m_{p}=\frac{a_{p} o_{p}}{-a_{p} o_{p}+b_{p}}
\end{aligned}
$$

In this formula, the subscript $\mathrm{p}$ means peak period.

Similarly, we can get the self-elasticity and cross elasticity coefficient of other time.1111

2. System operation constraints

(1) Power balance constraint

$$
\begin{gathered}
G_{\text {total }}(k)=G_{\text {self }}(k)+G_{\text {pur }}(k)+G_{\text {sell }}(k)-G_{\text {loss }}(k) \\
G_{\text {self }}(k)+G_{\text {sell }}(k)=G_{\text {gas }}(k)+G_{P V}(k)+G_{\text {wind }}(k) \\
=\int_{t=1}^{k} P_{\text {gas }}(t)+\int_{t=1}^{k} P_{P V}(t)+\int_{t=1}^{k} P_{\text {wind }}(t)
\end{gathered}
$$

In this formula, $G_{\text {total }}(k)$ means system total power demand of period k, $G_{\text {self }}(k)$ means system selfoccupied power of period $\mathrm{k}, G_{p u r}(k)$ means the purchasing electricity to the grid of period $\mathrm{k}, G_{s e l}(k)$ means on-grid energy of period $\mathrm{k}, G_{\text {loss }}(k)$ indicates system power consumption of period $\mathrm{k}, G_{g a s}(k)$, $G_{P V}(k), G_{\text {wind }}(k)$ indicate the generated energy of internal combustion engine, solar panels and wind turbines of period k, $P_{P V}(t), P_{\text {wind }}(t)$ and $P_{g a s}(t)$ represent generated power of PV units, wind turbine generators and gas turbine units of period $\mathrm{k}$.

(2) heat balance constraint

$$
\begin{aligned}
Q_{\text {recly }}+Q_{\text {gas }}+Q_{\text {solar }}= & \left(Q_{\text {cold }} / \eta_{\text {cold }}\right) H_{1}+\left(Q_{\text {hot }} / \eta_{\text {hot }}\right) H_{2} \\
& H_{1}+H_{2}=1 \\
Q_{\text {recly }}^{\text {gas }}= & q_{\text {gas }} \cdot\left(1-\eta_{\text {gas }}\right) \cdot \eta_{\text {recly }}
\end{aligned}
$$

In this formula, $Q_{\text {recty }}$ means the amount of waste heat recovery, $Q_{\text {gas }}$ means the heat of gas burn, $Q_{\text {solar }}$ means the heat of solar energy conversion, $Q_{\text {cold }}$ means the heat utilized by refrigerating unit, $\eta_{\text {cold }}$ means the efficiency of refrigerating unit, $Q_{h o}$ means the heat utilized by heat exchanger, $\eta_{h o t}$ means the efficiency of heat exchanger, $Q_{\text {ras }}^{\text {gas }}$ means the heat recycled afterheat of gas turbine, $q_{g a s}$ means the gas consumption of gas turbine, $\eta_{\text {gas }}$ means the generating efficiency of gas turbine, and $\eta_{\text {recly }}$ means the efficiency of heat recovery equipment.

\section{Solution of model based on PSO-EO algorithm}

Particle Swarm Optimizer algorithm is a stochastic global optimization technique and swarm intelligence algorithm, with simple principle and less parameters, but the algorithm has the problem of premature convergence and local convergence. Extremal Optimization algorithm does not converge to a state of equilibrium, and the fluctuation produced by the intermittent equilibrium makes the algorithm have better ability to search continuously and get rid of the optimal solution.

Based on this, in this paper, the EO algorithm and PSO algorithm are combined to propose a hybrid particle swarm optimization PSO-EO algorithm. In order to avoid the reduction of algorithm convergence, in this paper, the EO is set to be added to the PSO algorithm every h generation. The algorithm flow is as follows.

(1) Initialization related parameters, including search space, particle position and velocity, etc. Set number of iteration $\mathrm{k}=0$, control error $\lambda$.

(2) Calculate the fitness value fi of each particle in the current position, and calculate the corresponding pi and gi, that is, the optimal fitness values of the first I particles and their neighboring particles.

(3) The velocity and position of each particle is updated by iteration, the formula is as follows. 


$$
\begin{aligned}
v_{i d}(t+1) & =w \times v_{i d}(t) \\
& +c_{1} \times \operatorname{rand}() \times\left[p_{i d}(t)-x_{i d}(t)\right] \\
& +c_{2} \times \operatorname{rand}() \times\left[p_{g d}(t)-x_{i d}(t)\right] \\
x_{i d}(t+1) & =x_{i d}(t)+v_{i d}(t+1) \\
1 & \leq i \leq n \quad 1 \leq d \leq D
\end{aligned}
$$

Meanwhile, calculate corresponding pi and gi.

(4) If $\bmod (\kappa, \hbar)=0$, the corresponding optimal solution $y_{n}^{*}$ is used as the input of the EO algorithm, and find the optimal solution again. Otherwise, proceed to the next step.

(5) Set $\hbar=\hbar+1$, if $\left|y_{\hbar}-y_{\hbar-1}\right|<\lambda$, end; otherwise, turn to step 2 .

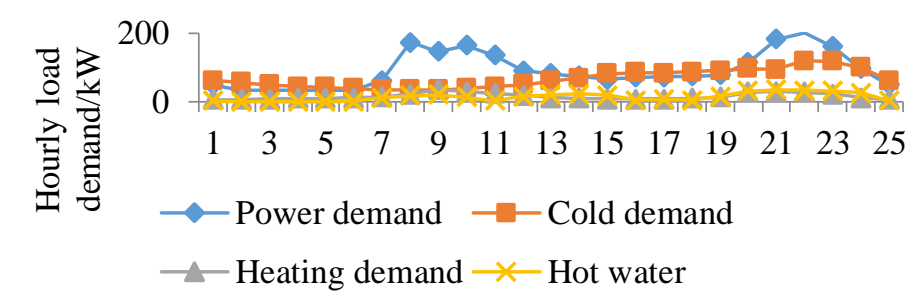

Fig. 2 Typical daily load demand of a regional energy Internet system in North China

\section{Example}

According to the operating parameters of a regional energy Internet system in China (table 1), and the electric, cold and heat load demand curve of a typical day of the system (fig.2). The results of the system are obtained by PSO-EO algorithm, as shown in fig.3-fig.6.

Table 1. Regional energy Internet system equipment technical parameters

\begin{tabular}{|c|c|c|c|c|c|}
\hline & $\begin{array}{c}\text { Operation cost / } \\
\text { (yuan/KWh) }\end{array}$ & $\begin{array}{c}\text { maximum } \\
\text { power } / \mathrm{kW}\end{array}$ & $\begin{array}{c}\text { minimum } \\
\text { power/kW }\end{array}$ & $\begin{array}{c}\text { Electrical } \\
\text { efficiency }\end{array}$ & $\begin{array}{c}\text { thermal } \\
\text { efficiency }\end{array}$ \\
\hline Wind turbine & 0.0450 & 50 & 0 & - & - \\
\hline PV unit & 0.0096 & 50 & 0 & $12 \%$ & - \\
\hline gas turbine & 0.064 & 80 & 25 & $30 \%$ & $54 \%$ \\
\hline power grid & - & - & - & $37 \%$ & - \\
\hline energy storage & 0.0450 & 30 & 0 & - & $51 \%$ \\
\hline $\begin{array}{c}\text { Solar hot water } \\
\text { boiler }\end{array}$ & 0.0050 & 20 & 0 & - & $102 \%$ \\
\hline $\begin{array}{c}\text { Natural gas boiler } \\
\text { Absorption } \\
\text { refrigerator }\end{array}$ & 0.0020 & 20 & 0 & - & - \\
\hline $\begin{array}{c}\text { Electric } \\
\text { refrigerator }\end{array}$ & 0.0008 & 30 & 0 & - & - \\
\hline heat exchanger & 0.0097 & 50 & 0 & & - \\
\hline
\end{tabular}




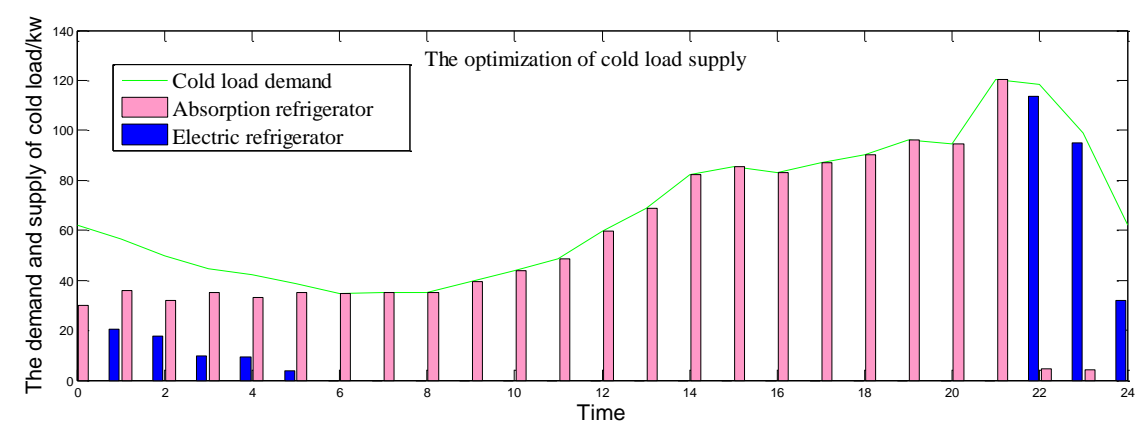

Fig.3 Results of cooling load supply optimization

As can be seen from Figure 3, there is less demand for the typical daily cooling load. The light condition is better of 8:00-17:00, therefore, the cooling load in the period can be supplied by an absorption refrigerator. In 17:00-22:00, gas turbine power generation waste heat can meet the cooling load demand of the period. The period 22:00-06:00 is the valley time of the electricity price in the area, so the cold supply is mostly supplied by electric refrigerator.

Similarly, the heat demand of this typical day is less, so the supply of hot water mainly supplied by solar water heater during the day of better light conditions. At night, 19:00-6:00, the hot water is
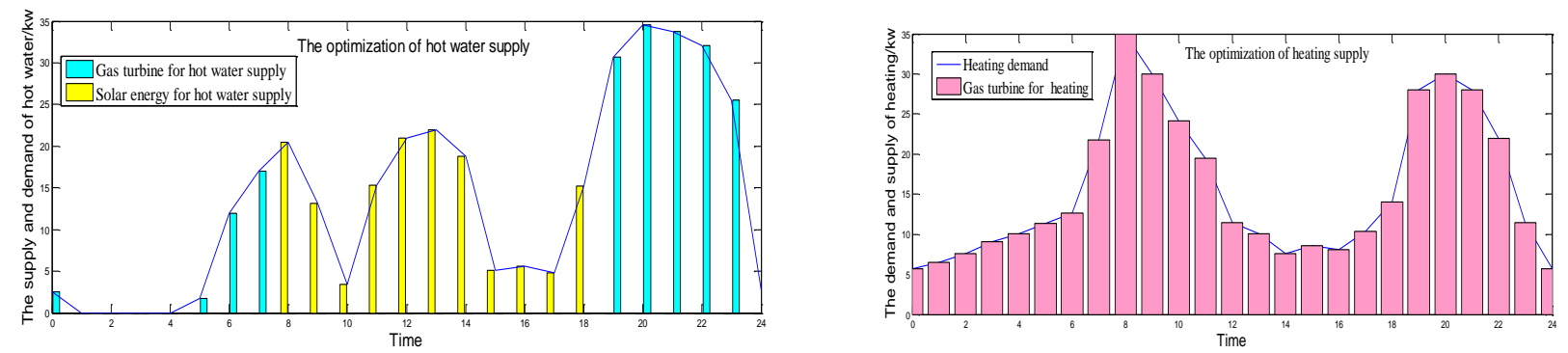

supplied by gas turbine waste heat. And the heating demand is meet by gas turbine totally.

Fig.4 Results of heat load supply optimization

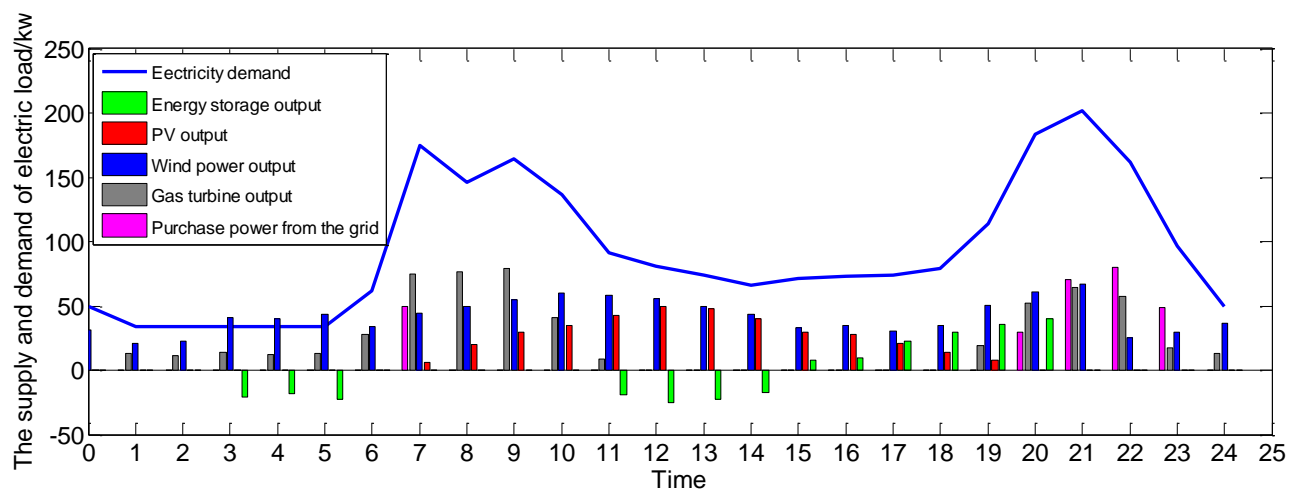

Fig.5 Power optimization results

As can be seen in Fig.5, electric load demand is supplied by gas turbine, distributed PV, distributed wind power and energy storage, purchase electricity to the power grid when the power is insufficient. At night, the wind speed is high, the load demand is low, part of the power generated by wind is stored by storage equipment. Meanwhile, at 11:00-14:00, the illumination condition is good, the wind force is strong, the distributed photovoltaic and wind power output is more, part of the power is stored by storage equipment. The period 17:00-20:00 is the peak hour, so the energy is released by the energy storage device and supplied to power users to relieve the peak demand for electricity generation. 22:00-06:00 is the trough period of summer electricity prices in the region, the wind power is utilized first, if not enough, through gas turbines and purchasing electricity from the power grid to meet the electricity demand. 
Table 2. Typical daily load transfer

\begin{tabular}{|c|c|c|c|}
\hline Roll out time & Transit time & Transfer amount $/ \mathrm{KW}$ & Duration/h \\
\hline $19: 00$ & $5: 00$ & 20 & 1 \\
\hline $19: 00$ & $6: 00$ & 15 & 1 \\
\hline $20: 00$ & $16: 00$ & 10 & 1 \\
\hline $20: 00$ & $16: 00$ & 10 & 1 \\
\hline $21: 00$ & $17: 00$ & 20 & 1 \\
\hline $21: 00$ & $17: 00$ & 10 & 2 \\
\hline $21: 00$ & $15: 00$ & 15 & 1 \\
\hline $21: 00$ & $6: 00$ & 10 & 2 \\
\hline $22: 00$ & $5: 00$ & 5 & 1 \\
\hline $22: 00$ & $6: 00$ & 5 & 1 \\
\hline $22: 00$ & $17: 00$ & 10 & 2 \\
\hline $23: 00$ & $7: 00$ & 5 & 1 \\
\hline $23: 00$ & $17: 00$ & 10 & 1 \\
\hline $23: 00$ & $17: 00$ & 15 & 1 \\
\hline
\end{tabular}

In addition, in this paper, the typical daily load transfer is calculated, as shown in table2, set the total transfer amount of each load should not exceed $30 \mathrm{~kW}$ at the same time. The transfer load can be transferred from the high price period to the low price period, which realizes the economy of the regional energy Internet, and also plays a good role in cutting the peak and filling the valley. In order to explain the economic benefits brought by the load transfer of the regional energy Internet, this paper calculates the system cost and energy saving and emission reduction rate of 2 cases on the basis of PSO-EO algorithm. Situation 1 is the transfer of controllable load, the system cost is 15572.4 yuan, the energy saving rate is $15.4 \%$. Situation 2 is the load side is not transferred, the system cost is $\$ 172$ million 928 thousand, the energy saving rate is $16.9 \%$. The cost of system in situation 1 is reduced by $9.95 \%$ compared to the situation of 2 , and energy saving rate has a certain degree of decline, which means that, after optimize the demand side load through load transfer, the system cost can be reduced effectively by peak valley spread, and demand response and energy cooperation can strengthen renewable energy consumption, enhance environmental benefits.

In addition, in order to compare the overall efficiency of the regional energy Internet, PSO-EO algorithm is used to obtain typical daily system cost and energy saving and emission reduction rate. According to table 3, compared with the traditional distributed CCHP system, regional energy Internet considering supply and demand sides can reduce the system cost from 19932.5 yuan to 15572.4 yuan, the cost is reduced by $21.9 \%$, energy saving rate of $15.4 \%$, reduction rate reached $19.1 \%$, the system can realize energy saving and emission reduction at the same time.

Table 3. Regional energy Internet summer system target optimization

\begin{tabular}{|c|c|c|c|c|}
\hline & \multicolumn{2}{|c|}{ Cost analysis } & \multicolumn{2}{c|}{$\begin{array}{c}\text { Energy saving and emission } \\
\text { reduction analysis }\end{array}$} \\
\hline & $\begin{array}{c}\text { System } \\
\text { cost(yuan) }\end{array}$ & $\begin{array}{c}\text { System cost } \\
\text { reduction (\%) }\end{array}$ & $\begin{array}{c}\text { System energy } \\
\text { efficiency (\%) }\end{array}$ & $\begin{array}{c}\text { System emission } \\
\text { reduction rate(\%) }\end{array}$ \\
\hline $\begin{array}{c}\text { Regional energy } \\
\text { Internet }\end{array}$ & 15572.4 & & 15.4 & 19.1 \\
\hline $\begin{array}{c}\text { Traditional distributed } \\
\text { CCHP system }\end{array}$ & 19932.5 & 21.9 & & \\
\hline
\end{tabular}

\section{Summary}

This paper comprehensively analyzes the regional energy internet system which integrates multiple types of energy sources and can realize multi-energy synergistic complementarity and constructs a multi-objective mixed integer non-liner programming model to optimize system operation strategy of regional energy internet. On this basis, PSO-EO algorithm is used to optimize multi-energy synergistic operation strategy of typical regional energy internet system in typical days combined with examples. Compared with the traditional combined cooling-heating-power system, the regional energy internet system is proved to have a better effect in realizing energy saving and 
emission reduction under the low cost, effectively stabilizing the fluctuations of wind energy, photovoltaic and other new energy, and promoting renewable energy consumption.

In this paper, there is room for further study. We only consider the steady state model when modeling but ignore transient characteristics. How to take the steady state and transient characteristics of the system into consideration synthetically in order to establish a more scientific and realistic model is the focus of future research.

\section{Acknowledgments}

This word is supported by the Science and Technology Project of State Grid Corporation of China (Contract Nomber, SGTYHT/15-JS-191) (Research on automatic demand response simulation technology adapting to the open electricity sale market in China)

\section{References}

[1]. WU Jun-xue. Research on Optimizing BP Neural Network Based on PSO-EO [J]. Science Technology and Engineering, 2010, 10(24):6047-6049.

[2]. ZHU Sha, CHEN Chen. A hybrid particle swarm optimization algorithm for solving cardinality constrained portfolio optimization[J]. Statistics \& Decision, 2016(10):64-67.

[3]. ZENG Ming, YANG Yongqi, XIANG Hongwei, WANG Lihua, ZENG Bo. Optimal dispatch model based on coordination between"generation - grid - load - energy storage" and demandside resource [J]. Electric Power Automation Equipment, 2016, 36(2):102-111.

[4]. LI Peng, HUA Haorui, CHEN Anwei, DI Kaili. Source-load-storage Coordination Partition Optimal Economic Operation of AC/DC Hybrid Microgrid Based on Bilevel Programming Model [J]. Proceedings of the CSEE, 2016, 36(24):6769-6779.

[5]. ZENG Ming, YANG Yongqi, LIU Dunnan, ZENG Bo, OUYANG Shaojie, LIN Haiying, HAN $\mathrm{Xu}$. "Generation-Grid-Load-Storage" Coordinative Optimal Operation Mode of Energy Internet and Key Technologies [J]. Power System Technology, 2016, 40(1):114-124.

[6]. XU Xiandong, JIA Hongjie, JIN Xiaolong, YU Xiaodan, MU Yunfei. Study on Hybrid HeatGas-Power Flow Algorithm for Integrated Community Energy System [J]. Proceedings of the CSEE, 2015, 35(14):3634-3642.

[7]. SUN Ke, WU Zhen, SHANG Nan, DUAN Guang ZHANG Lijun, BAO Minglei, LIU Hanlin, DING Yi, FAN Juanjuan, SHEN Liang. Provincial regional Energy Internet framework and development tendency analysis [J]. Power System Protection and Control, 2017,45(5):1-9.

[8]. OUYANG Yi, YANG Jie. Path and practice of energy Internet technology [J]. ENERGY OF CHINA, 2017(2).

[9]. ZHU Xiaojun, ZHANG Chao, WU Haibin. Research on practice and planning of energy Internet planning in Sino German Eco Park [J]. Energy Conservation, 015(10):9-15.

[10]. CHEN Chong, WU Yue. Study on Smart Park 2.0 Based on the Concept of Energy Interconnection and "Internet +"'[J]. ELECTRIC POWER ICT, 2016(4):22-26. 